\title{
Professional Languages and Implications for Engineering Management Education
}

\author{
Ted Eschenbach, Catherine Frank, Patricia Linton, and Robert Madigan \\ University of Alaska Anchorage/Engineering Management Journal/UAA/UAA
}

English composition courses teach basic writing skills — often relying on the Modern Language Association (MLA) style. However, dramatically different writing styles have arisen in some professions, and skill with them must often be developed within the discipline. Often disciplinespecific styles are linked to the discipline's paradigms for research and practice. ${ }^{4 \& 5}$

For example, the MLA and the American Psychological Association (APA) styles are distinct, and those styles are echoed throughout the literature of their respective disciplines. Students or faculty who have not mastered the appropriate style may find that their work is judged more harshly by their teachers or peers. Strongly technical disciplines such as chemistry and mechanical engineering place relatively less emphasis on writing and their style guides are less widely distributed. Nevertheless, violations of a journal's or a proceedings' style clearly affect a paper's substantive credibility. Moreover, the potentially disparate technical styles are brought together in engineering management (EM), which does emphasize writing and which brings together technical, business, and behavioral elements for both practitioners and academics.

\section{Literature Review}

Contemporary English composition texts ${ }^{3}$ present the APA style as having standing comparable with the MLA style. To illustrate the ubiquity of these styles and their detail, the APA style manual was selling at the rate of 200,000 copies annually in 1990, and its 1994 edition has 368 pages. Obviously the APA manual was and is successful in presenting, in a logical, concise, and useful manner, the basic tenets of technical writing. Disciplines that are even more highly technical than psychology embrace the same basic technical writing principles that the APA manual purports. Indeed many of these disciplines use publications that reiterate writing principles that also happen to be found in the APA manual but that address the discipline-specific writing and styling needs of those who wish to publish in the field, such as biology ${ }^{2}$.

However, for our purposes it is more relevant to examine what is implicitly defined as good writing by journals in a variety of disciplines. This work is tightly linked to work Madigan and Linton ${ }^{4} 5$. Another particularly useful work examined journals in biology, sociology, and literary criticism ${ }^{1}$.

All engineering journals have explicit or implicit styles, and IEEE even publishes a journal on professional communications. However, there does not seem to be the same unanimity that prevails in disciplines such as psychology. Thus, we were unable to identify a comparable style that is defined as appropriate across the spectrum of engineering disciplines. 


\section{Components of a Disciplinary Style}

Disciplinary styles can be distinguished by conventions for structure, reference, and language. In discussing the use of these conventions within EM, we find a useful distinction between literature directed at academics and that directed at practitioners. However, we want to emphasize that this work is currently conceptually based and that we intend to follow it with empirical work that analyzes articles in a data-based way. For example, future work will measure the number of citations per 100 words, rather than relying on judgments from reading or editing journals.

Structural conventions define an argument's flow. For example, the APA style calls for sections on introduction, method, results, and discussion, with appropriate subheads as needed as cues for the reader. The style is linked to an ideal method for conducting scientific research. Literary criticism and other humanities often follow a different structure. This might be asserting a thesis followed by insight that supports the thesis, or perhaps presenting an extensive quote or anecdote, followed by the central insight, and finally support for the insight. Language ties the ideas and arguments together so that the text may flow with few or no subheads.

In EM we find at least two somewhat divergent structural approaches, both of which depend heavily on subheads to alert the reader as to the structure. Articles written principally for academics, such as those found in IEEE Transactions on EM, are often structured similarly to the APA style.

However, articles written principally for practitioners, such as a significant portion of the articles found in Engineering Management Journal (EMJ), are often influenced by the style of the one-page business memo. This memo opens with a recommended action, followed by a description of the alternatives and a summary of the key reasons for making the recommended choice. Details are included as follow-up appendices. While a 6 to 10 page article is obviously longer than a one-page memo, the memo's structure of key result or recommendation first modifies the common technical writing structure of introduction, method, results, and discussion. These articles will often include the key result in the abstract, and in a somewhat extended form in the introduction. Thus readers may use the abstract, first paragraph or first section to decide whether to read further.

Conventions of reference focus on citations and quotations. In all fields appropriate citations establish the author's credentials as a master of the field's literature. However, in many empirical disciplines, citation selection and placement are key, and discussion is not. Simply listing citations is acceptable. Similarly, paraphrased summaries of key processes, alternatives, and conclusions are used to establish an article's ideas in the context of or in contrast to existing work.

In many humanities, simply listing citations seems superficial. Instead analysis of selected references anchors the discussion by defining areas of agreement and disagreement. Also, because the specific language is often quite important, long quotations are acceptable or even desirable.

The reference style of academically focused EM articles is more similar to the APA style. Moreover, the references are often numbered, as they are in this paper. The result is a denser text that many will read with a finger stuck in the reference page and that others will find less interesting or more intimidating. Similarly, striking quotes or anecdotes are often rare. The rephrasing emphasizes the 
ideal of objectivity, where only the ideas, not the language or the presenter, matters. Note that distorting sources is wrong but that accommodations that avoid clarifications or differentiations that seem like quibbling are acceptable.

On the other hand, articles aimed at practitioners tend to have shorter reference lists. The text usually indicates why they are included, and the text reference is usually by name, which enables the referenced material to be easily identified and recalled. For example, by the second citation, I will know to what "(Babcock, 1996)" refers. Including memorable anecdotes or quotes is also considered to be desirable. These quotes are typically accompanied by analysis and discussion. While using boxed quotes in a larger point size is a page layout/graphic design concept, journals which add this to articles are quoting the article within the article. These self-quotes are typically chosen because of their vivid language, striking metaphor, or anecdotal importance. Thus, this type of quoting also serves as an example of the next set of conventions concerning language.

Conventions of language focus on the importance of language, on describing disagreements, and on the language of conviction. In the humanities, language is often central with vivid metaphors and active language. In the more empirical disciplines, language is not. In fact, a rhetoric of objectivity may use passive voice ("data were collected") and ascribe agency to inanimate objects ("the data show"), both of which emphasize the data, not the presenters/doers. Using synonyms provides another example of distinctions between writing in literature (synonyms are good) and writing in technical reports (say it exactly the same way each time unless a distinction is being made).

In many technical disciplines the most important characteristic is clarity, as the experimental methods and results must be described without ambiguity. However, because this writing is intended to inform efficiently, a writing virtue almost as important is brevity. Thus the paradigm is that the methodology and the results provide the interest, and that the writer need not provide language that is entertaining or interesting.

Here again, the more academic articles in EM follow the more empirical disciplines. However, while practitioner-focused articles are often highly empirical, they seem to value language that is memorable and entertaining rather than boring.

Similarly, in the more empirical disciplines, disagreement tends to be expressed as "newer data are somewhat contradictory with earlier results," which focuses on the process and the data, not individuals. In history, disagreement tends to be gentle, as in "a sunnier view of the material suggests." In contrast, in literary criticism, the disagreement may verge on strident, for example, "truculently persist[ing] in crediting the discredited." In this case, both practitioner- and academicoriented EM writings tend more to the process focus of the empirical disciplines, with perhaps some tendency to gentle disagreement as in history.

On the other hand, with respect to the strength with which conclusions are stated, the EM journals again differ. The academic journals adopt an empirical style similar to APA including the style of hedging. Here appropriate hedging conveys that new data may imply future revision. On the other hand, more practitioner-focused articles are clearly directed by the need to make a persuasive case so that the recommended alternative ( $a$ la the business memo) is implemented. 


\section{Conclusions}

In contrast to disciplines such as psychology, EM brings together individuals of many disciplinary backgrounds; thus it lacks a single style. EM journals also consciously match their individual styles to their intended audiences. The lack of a single style requires educators who write papers to be more aware of the style for the desired outlet. They cannot simply rely on an acquired, tacit knowledge that fits all outlets.

Similarly, significant implications exist for EM education. Our students come from a variety of backgrounds, and our literature overlaps with industrial engineering, business and public administration, psychology, the sciences, and all other engineering disciplines. As such our students do not have consistent guidance, and the students and some (or most) faculty are unaware of the impact of writing with a style that the reader finds inappropriate or that renders the conveyed information unusable.

\section{References}

1. Bazerman, C. (1981). "What written knowledge does: Three Examples of Academic Discourse," Philosophy of the Social Sciences, 11, pp. 361-387.

2. CBE Style Manual (1983). Council of Biology Editors Style Manual Committee

3. Hacker, D. (1995). A Writer's Reference, $3^{\text {rd }}$, St. Martin's Press.

4. Linton, P., R. Madigan, and S. Johnson. (October 1994). "Introducing Students to Disciplinary Genres: The Role of the General Composition Course," Language and Learning Across the Disciplines, 1(2), pp. 63-78.

5. Madigan, Robert, Susan Johnson, and Patricia Linton. (June 1995). "The Language of Psychology: APA Style as Epistemology," American Psychologist, 50(6), pp. 428-436.

\section{Biographical Information}

\section{TED G. ESCHENBACH}

He is the founding and current editor of EMJ ('97 is Volume 9). He has taught at UAA, the Naval Postgraduate School, and the Univ. of Missouri-Rolla (Robert Koplar Professor of EM). He earned his Ph.D. in IE from Stanford, and his research focuses on managing technology and engineering economy. The second edition, of his Engineering Economy: Applying Theory to Practice, Irwin/McGraw Hill should be available in late ' 97.

Contact information: School of Engineering, University of Alaska Anchorage, 3211 Providence Drive, Anchorage, AK 99508, 907-786-1021, fax -1079, aftge@uaa.alaska.edu

\section{CATHERINE M. FRANK}

She is the managing editor of $E M J$, where she has controlled the journal's language since its inception. She has worked for General Physics Corporation and Battelle Project Management Division and is currently self-employed as a technical editor.

\section{PATRICIA W. LINTON}

She is an associate professor of English at UAA. Her research interests include studies of contemporary literature as well as discourse theory and cognitive approaches to writing. In collaboration with Robert J. Madigan, she has published several articles focusing on comparative analyses of disciplinary discourse.

\section{ROBERT J. MADIGAN}

$\mathrm{He}$ is a professor of psychology at UAA with research interests in language processing, writing genres, and the cognitive operations involved in writing. He and Patricia Linton have published papers on disciplinary writing styles for audiences in both psychology and English. He earned his $\mathrm{PhD}$ in experimental psychology from UCLA. 